\title{
1. Regional and international treaties on intangible cultural heritage: between tradition and contemporary culture
}

Lucas Lixinski

\section{INTRODUCTION}

In thinking about international legal instruments safeguarding intangible cultural heritage (ICH), the most important treaty is the 2003 Convention for the Safeguarding of the Intangible Cultural Heritage (ICHC or 2003 Convention). Approved under the aegis of the United Nations Educational, Scientific and Cultural Organization (UNESCO), it is the key international treaty dedicated to $\mathrm{ICH}$, and the result of a long negotiation process, going back over 30 years. ${ }^{1}$

But this treaty, successful as it is, is not the only international legal initiative that considers ICH. UNESCO is an organization that aims to cover the entirety of the world (or at least its 195 Member States). But the legal treatment of culture has been traditionally considered to be best when it is closer to the ground. To that effect, a number of regional organizations, covering certain continents or geographic regions, have also engaged in law-making with respect to cultural heritage. ${ }^{2}$

Regional organizations offer the advantage of being closer to the culture they wish to regulate. Additionally, because they represent regions of usually like-minded States, a sense of shared culture and identity usually pervades these organizations, and deeply influences their mandates with respect to the regulation of culture more broadly, and cultural heritage in particular. These initiatives usually have to do with fostering a sense of shared identity in the region. They can, and often do, go farther than initiatives under universal bodies like UNESCO, which always run the risk of providing the lowest common denominator as the result of compromises among several cultural, political and legal traditions.

1 For more on the history of cultural heritage law-making see: Lucas Lixinski, Intangible Cultural Heritage in International Law (Oxford University Press 2013).

2 For a broader exploration of regionalism in the field, see Janet Blake, International Cultural Heritage Law (Oxford University Press 2015). 
Regionally, these traditions are more uniform, at least on the surface, allowing regional bodies to at least in theory prepare stronger instruments to protect heritage.

The dark side of this story about regionalism is that regional organizations, in their ability to enact stronger instruments, and advancing their constitutional mandates to foster a common identity, play a much stronger role in delimiting the boundaries of 'authorized' common identity, and therefore 'authorized' heritage. ${ }^{3}$ Regional organizations, therefore, run the risk of being more selective in authorizing heritage than UNESCO often can be. ${ }^{4}$ But a few tenets are shared, as this chapter will explore.

This chapter will consider two key international instruments with respect to ICH, the 2003 Convention and the Council of Europe's 2005 Faro Framework Convention on the Value of Cultural Heritage for Society (Faro Convention). The Faro Convention in particular is chosen because of its importance in Europe. In doing so, the chapter will consider not only what these two treaties can do for ICH separately, but also their interrelationships. In the background are the tensions, highlighted above, about the role of regionalism in safeguarding cultural heritage more generally, and ICH in particular. By highlighting those tensions, I hope to show that the avenues for considering contemporary $\mathrm{ICH}$, largely closed by the ICH Convention, are reopened in its interaction with the Faro Convention.

What follows explores the two key treaties in several respects: the definitions of heritage in each treaty; key mechanisms for safeguarding $\mathrm{ICH}$; gaps in implementation; and the room for contemporary manifestations of culture to be considered as heritage. The ICHC is analyzed first.

\section{THE INTANGIBLE CULTURAL HERITAGE CONVENTION: INTANGIBLE HERITAGE DEFINED AS TRADITION}

One important definitional issue in the 2003 Convention is the idea that ICH refers not to the cultural objects, but rather to the social and cultural processes of which these objects are but the products. This was an important change of focus that happened gradually in heritage studies, and one that was decisively pushed into the ICHC by the Organization of

3 Laurajane Smith, Uses of Heritage (Routledge 2006).

4 Lixinski (n 1) 67-103. 
African Unity (later replaced by the African Union), alongside the group of experts responsible for the initial drafting of the Convention. ${ }^{5}$

The choice of the term 'intangible cultural heritage' has been criticized by some scholars. ${ }^{6}$ The term makes sense within the administrative logic of UNESCO, precisely because of its opposition to tangible cultural heritage, which was addressed in other UNESCO instruments. However, to conceive of this type of heritage as 'intangible' in theory weakens its worth, rendering it disconnected and conveying the impression that its existence is ethereal or irrelevant. Further, the term 'intangible heritage' arguably weakens the status of traditional culture in legal practice, and can lessen the possibilities of protection. ${ }^{7}$

This seemed to be the best option, though, despite criticism. 'Folklore' was a term already charged with the product-oriented connotations of the 1989 Recommendation, as well as being perceived to imply banality within sacred traditions, ways of life, and cultural identity generally. 'Treasures', on the other hand, was seen as being too paternalistic (and too oriented towards a 'westernised' conception of heritage shaped after the World Heritage Convention). Further, 'oral heritage' was considered too narrow in scope, ${ }^{9}$ while 'traditional culture' seemed to obliterate the fact that ICH is about living cultures being constantly recreated. ${ }^{10}$

What exactly falls under the definition of intangible cultural heritage', however, was the object of much debate during the meeting of the Restricted Drafting Group in 2002. Three difficulties were identified: (1) that any such category of intangible heritage would be too broad; (2) conversely, that a list would run the risk of being too specific and restrictive; and (3) that the different views of States should be harmonized with respect to their perceptions of what ICH is. The (eventually adopted) flexible approach was identified as being necessary, taking into account UNESCO Member States' views on the topic, but at the same time

5 Noriko Aikawa-Faure, 'From the Proclamation of Masterpieces to the Convention for the Safeguarding of Intangible Cultural Heritage', in Laurajane Smith and Natsuko Agakawa (eds) Intangible Heritage (Routledge 2009) 23.

6 See generally Lixinski (n 1) 34-5.

7 See Anthony McCann and others, 'The 1989 Recommendation Ten Years On: Towards a Critical Analysis', in Peter Seitel (ed.), Safeguarding Traditional Culture: A Global Assessment (Smithsonian Institution 2001) 60.

8 Janet Blake, Commentary on the UNESCO2003 Convention on the Safeguarding of the Intangible Cultural Heritage (Institute for Art and Law 2006) 22, 32.

9 Aikawa-Faure (n 5) 27.

10 Richard Kurin, 'Safeguarding Intangible Cultural Heritage: Key Factors in Implementing the 2003 Convention' (2007) 2 International Journal of Intangible Heritage 10, 12. 
avoiding overlaps with the mandates of other international organizations (most notably the World Intellectual Property Organization (WIPO) and the World Trade Organization (WTO)), while attending to the concerns of experts and facilitating legal protection. ${ }^{11}$ Ultimately, the definition seems to have taken these factors into account, by weaving an open definition, with a non-exhaustive list of examples, and avoiding using examples from the area of IP law (out of respect for the division of work with the WIPO, but also with the consequence of autonomizing intangible heritage beyond the domains of IP).

The definition of ICH in the Convention, ${ }^{12}$ importantly for our purposes, speaks of the need for ICH to be transmitted from one generation to the next, with a view of giving communities a sense of continuity. In this respect, the definition seems to sit uneasily with more contemporary manifestations of ICH. While it embraces, unlike other heritage treaties, the current engagement with and uses of the heritage (by defining ICH as 'living heritage'), it imposes a threshold requirement of intergenerationality, which means that ICH needs to be practiced by at least two generations (and presumably having been created at least in the generation prior to the one seeking legal recognition) for it to fit in the definition of the ICHC. The Convention, and its drafting history, are unclear as to how they define generation, or how long a generation would be.

The purposes of the Convention, as determined in Article 1, are four: (1) to safeguard ICH; (2) to ensure respect for the ICH of communities, groups, and individuals; (3) to raise awareness; and (4) to provide

11 UNESCO, Preparation of a preliminary draft International Convention on the Intangible Cultural Heritage, Meeting of the 'Restricted Drafting Group' (RDG) in Paris, 20-22 March 2002-Outline Work Plan, paras 30-31.

12 Convention for the Safeguarding of the Intangible Cultural Heritage, Paris, 17 October 2003. Entry into force: 20 April 2006. Article 2 reads:

Definitions. For the purposes of this Convention, 1. The intangible cultural heritage' means the practices, representations, expressions, knowledge, skills as well as the instruments, objects, artefacts and cultural spaces associated therewith - that communities, groups and, in some cases, individuals recognize as part of their cultural heritage. This intangible cultural heritage, transmitted from generation to generation, is constantly recreated by communities and groups in response to their environment, their interaction with nature and their history, and provides them with a sense of identity and continuity, thus promoting respect for cultural diversity and human creativity. For the purposes of this Convention, consideration will be given solely to such intangible cultural heritage as is compatible with existing international human rights instruments, as well as with the requirements of mutual respect among communities, groups and individuals, and of sustainable development. 
international cooperation and assistance. This provision lays down the foundations of the safeguarding system created by the Convention. This system comprises a set of lists, some institutional machinery, and a fund.

On the institutional machinery, there are two organs created under the ICHC, the Intangible Heritage Committee and the General Assembly of States Parties. The General Assembly of States Parties is created by Article 4 of the 2003 Convention, and it represents a substantial shift from the 1972 World Heritage Convention, which does not contain provisions for a similar organ. This is symptomatic of a greater concern among States participating in the drafting over their sovereignty, especially when dealing with matters as sensitive as culture (living cultures, to be more specific) and claims by communities and groups. It was felt that sovereignty should be strengthened, and one of the tools for that purpose was to create an Assembly of Parties to be the supreme authority on most matters regarding the intangible heritage convention. ${ }^{13}$ Regional systems, as discussed below, are in theory less concerned with this preservation of sovereignty, as they rely on a common ground, a safe space in which the delegation of sovereignty even in matters as sensitive as culture can be done more easily.

The Intangible Heritage Committee, on the other hand, was created with the idea that intangible heritage is an area that requires a high level of expertise, due to its complexity, and that this level of expertise could only be reached by a Committee, inspired by similar experiences in the area of international environmental law. ${ }^{14}$ Article 5 of the 2003 Convention determines that the committee shall be composed of representatives of 24 States Parties to the Convention, elected by the General Assembly. It is also an intergovernmental organ, but one with reduced participation of States Parties. In this sense, then, the Committee is yet another layer of sovereignty imposed upon the regulation of ICH concerns.

The 2003 Convention also provides for the safeguarding of intangible cultural heritage at the national level. In fact, the creation of national systems of safeguarding, including awareness-raising, education, and a participatory approach are central to the Convention's success. ${ }^{15}$ Article 11 imposes the core obligations in terms of safeguarding, and it determines that States shall take the necessary measures to ensure the safeguarding of $\mathrm{ICH}$, including ensuring the participation of communities, groups, and NGOs in the process of identification and definition of the intangible heritage in each State's territory. This latter provision reflects the concern with

\footnotetext{
13 Blake (n 8) 46.

14 Ibid., 45.

15 ibid., 59.
} 
the fact that the most important obstacle to the safeguarding of intangible heritage is precisely the lack of knowledge by each State of the knowledge present in their territories. ${ }^{16}$

This issue is addressed by the obligation imposed upon States Parties to make an inventory of the manifestations of intangible cultural heritage in their territories (Art. 12). These inventories must be prepared by each State, periodically updated, and are an important part of the reporting that each State Party has to undertake and produce to the ICH Committee (Art. 29).

There are also other forms of safeguarding required from States Parties (Art. 13). These include policies to promote ICH in society as an important functional part of the social and cultural fabric, the establishment of competent bodies to deal with ICH and the adoption of other, legal, technical, administrative, and financial measures to foster ICH and ensure access to it while respecting communities and customary practices on the matter.

One criticism of this provision is that it determines that States Parties 'shall endeavour to' adopt the measures listed in this Article. This language of course has the effect of weakening this provision and the measures mandated by it, making them subsidiary to the obligation of creating national inventories. ${ }^{17}$ In this sense inventorying becomes the main safeguarding tool in the Convention's system, at least inasmuch as national measures are concerned.

Article 14, also determining that States 'shall endeavour' to adopt certain measures, speaks of measures aimed at education, awarenessraising, and capacity building. This provision, with its strong emphasis on the educational component of ICH, is an important innovation with regard to the 1972 World Heritage Convention, and one that illustrates the important shift in focus between the two instruments. ${ }^{18}$ To the extent that ICH refers to living cultures, the perpetuation of ICH as a living culture requires that younger generations are educated to become future bearers of these traditions. This is the sense given to educational measures in this Article.

Finally, Article 15 determines that, at the national level, communities, groups, and individuals concerned with ICH shall participate in policy-making about, and management of, their own intangible heritage. This provision is distinct precisely to emphasize the importance of the role attributed to

\footnotetext{
Ibid., 61-2.

Ibid., 66.

Ibid., 74.
} 
communities. ${ }^{19}$ While this is a valuable development, I have argued elsewhere that this inclusion is limited to the national level (where there is much less international control, and less uniformity of practice). ${ }^{20}$ Furthermore, it does not necessarily compensate for the overall exclusion of community input during the drafting of the Convention and its safeguarding system.

The safeguarding of intangible heritage at the international level happens primarily through intangible heritage lists. One of them is the 'Representative List of the Intangible Cultural Heritage of Humanity' (Art. 16), while the other is the 'List of Intangible Cultural Heritage in Need of Urgent Safeguarding' (Art. 17). It is important to note that only the first list is called a 'representative' list, while the other includes, at least in theory, all forms of intangible heritage in grave risk of disappearance. These two mechanisms reflect the structure of the World Heritage Convention, and, while salutary in their effort to raise awareness to ICH worldwide, also can have the effect of hierarchizing ICH.

Article 18 provides for programmes, projects, and other activities for the safeguarding of intangible heritage, and determines that the Committee (upon approval by the Assembly) shall select the ones that best reflect the objectives of the Convention. In this way, an inventory of best practices, so important for the implementation of the Convention for the reasons listed above, can be created. ${ }^{21}$ These inventories of best practice are not restricted to the ICH itself, but rather to the methods of safeguarding, and can therefore accommodate new technologies and contemporary interactions with traditional culture fairly easily.

Article 19 determines international cooperation for the safeguarding of intangible heritage, including the exchange of information and joint initiatives by States Parties. Article 20 determines the purposes of international assistance, while Article 21 outlines the forms of international assistance. States may further request international assistance for the safeguarding of intangible heritage in their territories (Art. 23). This international assistance may be financial in nature, with money drawn from the fund created by the Convention. And any funds allocated shall generally be met by the State Party as a means to prove interest also from the State Party in protecting its intangible heritage (Art. 24.2). ${ }^{22}$ One important feature of these requests is that only States can ask for such assistance, in the same way that only States can propose manifestations of heritage to the lists created by

\footnotetext{
Ibid., 76.

Lixinski (n 1) 37-8.

Blake (n 8) 86-8.

Ibid., 102.
} 
the Convention. This is yet another feature of the strict sovereignty upon which the Convention system is built. ${ }^{23}$

The 'Fund for the Safeguarding of the Intangible Cultural Heritage' is created by Article 25 of the Convention, and it is an important mechanism to access resources for safeguarding $\mathrm{ICH}$. The resources of the fund come from contributions made by States Parties to the Convention, voluntary contributions from States (whether a party to the Convention or not), organizations from the UN system, private organizations and individuals, any other income deriving from the fund itself (investments, for instance), and specific fund-raising activities (Art. 28). Article 26 offers a creative compromise to the difficult negotiation of the financial commitments of States, as it creates a duty of contribution to which States can submit opt-out declarations (Art. 26.2). And, even when a State does deposit a declaration to such effect, it is still under an obligation to 'endeavour' to withdraw the declaration and contribute fully to the system (Art. 26.3).

Community involvement is an important part of the system created by the 2003 Convention, ${ }^{24}$ a feature shared with the Faro Convention. Communities are defined in a fairly broad way. To be more precise, it is for each State Party to define community according to their own domestic rules. While that in theory encompasses a wider range of participants, it can also be seen as allowing for the manipulation of the definition by States, at the expense of dissonant minority groups. ${ }^{25}$

The ICH Convention is very much focused on protecting State sovereignty. This approach seems to have been the necessary compromise to approve the Convention, and it substantially weakens the reach of the instrument. Plus, it does not protect intangible heritage from being harmed by the State in which it originates, at least to the extent that the ultimate control over what constitutes intangible heritage and what may be worthy of protection, for the purposes of the Convention, still rests with the States Parties. In this sense, then, the Convention is incapable of offering remedies against misappropriation by third parties, particularly when the third party is the State.

23 Ibid., 99.

24 Janet Blake, 'UNESCO's 2003 Convention on Intangible Cultural Heritage: The Implications of Community Involvement in "Safeguarding"' in Laurajane Smith and Natsuko Akagawa (eds), Intangible Heritage (Routledge, 2009) 62; Aikawa-Faure (n 5) 37.

${ }_{25}$ See, e.g., Lucas Lixinski, 'Heritage Listing as a Tool for Advocacy: The Possibilities for Dissent, Contestation and Emancipation in International Law through International Cultural Heritage Law' (2015) 5(2) Asian Journal of International Law 387. 
One example of this State-centrism is the fact that the General Assembly is the controlling body behind the Convention, as explained above. If States Parties choose to overlook the recommendations of UNESCO (done in the framework of the UNESCO Secretariat's role of assisting the operation of the Intergovernmental Committee), little can be done about it. Intangible heritage, then, becomes a highly politicized matter, as are most matters related to identity.

Part of this excessive focus on sovereignty stems from the same justification used to explain the international initiative that led to the drafting of the Convention. According to commentators, there was deep concern about the protection of ICH at the international level, and what it might imply. States were concerned that, by elevating local cultures to international status, an instrument might give rise to claims against the State, including eventual claims for statehood. Most importantly, though, there was a concern expressed by several scholars and some States that to elevate intangible heritage to an international concern would necessarily take the heritage outside its original cultural context, destroying intangible heritage by the very act of attempting to give it international protection. This paradox was solved by the affirmation that intangible cultural heritage is not the heritage of mankind; rather, it is the interest in the protection of local cultures and the intangible heritage associated with it that is an international concern. ${ }^{26}$ The international concern is thus an instrumental, rather than a substantive, one. This compromise of sorts is reflected in the Preamble and Article 19(2) of the Convention, the latter determining that 'States Parties recognize that the safeguarding of intangible cultural heritage is of general interest to humanity'. The interest is the safeguarding, not the heritage per se.

Further, the internationalization of intangible heritage can also be beneficial for the very perpetuation of it. There have been instances (the Argentinean Tango being one of the most prominent) in which communities only felt pride in their heritage after its exposure to the 'outside world', where it was well-received and praised. ${ }^{27}$

When drafting what became the 2003 Convention, the experts involved in the process had three alternatives: (1) drafting an instrument based on IP solutions and sui generis mechanisms adapted from IP tools (which was soon seen as limited in reach and generally inappropriate for intangible

\footnotetext{
26 See generally Blake (n 8) 90.

27 For the account of how Tango was 're-appropriated' by Argentineans and became their national intangible heritage after being praised abroad, see Susan Scafidi, Who Owns Culture? Appropriation and Authenticity in American Law (Rutgers University Press 2005) 28-31.
} 
heritage protection) $;^{28}$ (2) drafting an instrument based upon the model of the 1972 World Heritage Convention; or (3) drafting an instrument in between these two alternatives. Early thinkers on this process regarded the hybrid as the best alternative. ${ }^{29}$

However, in the end the choice was made by intergovernmental experts (with the support of a large number of States) ${ }^{30}$ to follow the model of the 1972 World Heritage Convention, as a means to guarantee immediate acceptance of the Convention and fast ratification, and also because the listing model of the 1972 Convention had proven to be an effective tool in raising awareness to cultural heritage and stimulating the development of policies aimed at the protection of heritage. ${ }^{31}$ This choice offered several advantages, as it would promote awareness to $\mathrm{ICH}$, it created a financial mechanism to foster $\mathrm{ICH}$, and it created a necessary machinery to oversee the implementation of the treaty. There was a concern with the idea that the listing would create an unnecessary hierarchy by safeguarding only a limited number of manifestations of intangible heritage..$^{32}$ It should be stressed that, even though the initial draft as proposed was in many ways a mirror of the World Heritage Convention, the experts who worked in the drafting of the ICH Convention managed to move away from it in many respects, as highlighted above. The effort of the experts is noteworthy, as it produced a document that was easily recognizable and acceptable to States, while at the same time moving away from such a model in important ways.

Be that as it may, the fact is that the main goals of the model (raising awareness and stimulating the development of protective policies) were achieved. However, one wonders whether the price paid for it (that is, the lack of a more fitted international instrument, or one with more 'teeth') was worth it, in the long run.

The ICHC, however, does not operate in a vacuum. As such, the text of the convention acknowledges its relationship with other instruments. ${ }^{33}$ The system created by the 2003 Convention was meant to be, from the very beginning, complementary to regimes that could be created by

28 Blake (n 8) 13.

29 Lyndel V Prott, 'Some Considerations on the Protection of the Intangible Heritage: Claims and Remedies', in Seitel (n 7) 110; Blake (n 8) 6.

30 UNESCO General Conference, Oral Report of the Chairperson of Commission IV, Doc.31 C/INF.24, of 12 November 2001.

31 UNESCO, Final Report International Meeting of Experts on Intangible Cultural Heritage: Priority Domains for an International Convention (Rio de Janeiro, Brazil, 2002); Blake (n 8) 4.

32 Blake ibid., 13.

33 ICH Convention (n 12), Art. 3. 
other specialized agencies. ${ }^{34}$ The commitment to complementarity is true particularly regarding intellectual property (IP) protection, which was, and still is, being developed by the WIPO at international level. ${ }^{35}$ States participating in the negotiations of the ICHC were well aware of the WIPO's efforts, and wanted to avoid any possible overlaps between the work of the two organizations. ${ }^{36}$ This is one of the reasons why, for instance, there was resistance in referring to 'individuals' in the text of the Convention, since this might suggest a possible crossover with the IP regime (which includes rights ascribed to individuals). ${ }^{37}$

The idea behind Article 3 of the 2003 Convention is also that of complementarity, meaning it is meant to avoid clashes. This provision determines that the ICH Convention is not to be interpreted in any way contrary to other international obligations, particularly those undertaken under the 1972 World Heritage Convention (Art. 3.a) or other IP and environmental agreements (Art. 3.b).$^{38}$ In a way, thus, it is meant to strengthen international safeguarding across the board. The World Heritage Committee produced a document before the entry into force of the 2003 Convention outlining the need for integrated approaches for the safeguarding of cultural heritage, marking another point of distinction from the World Heritage Convention. The Yamato Declaration on Integrated Approaches for Safeguarding Tangible and Intangible Cultural Heritage calls upon UNESCO to, among other things, adopt integrated approaches in all its heritage programmes, taking into account the complementarity of the regimes created by the different instruments and the idea that all stakeholders can take better advantage of the regimes if integrated approaches are adopted. ${ }^{39}$

Not necessarily envisaged by the drafters of the ICHC is the relationship between the treaty and heritage instruments under the umbrella of regional organizations. Those possible relationships raise questions

34 UNESCO, Final Report on the International Meeting of Experts.

35 For more on the promises and pitfalls of the relationship between UNESCO and WIPO on this question see: Lucas Lixinski and Louise Buckingham, 'Propertization, Safeguarding and the Cultural Commons: The Turf Wars of Intangible Cultural Heritage and Traditional Cultural Expressions' in Valentina Vadi and Bruno de Witte (eds), Culture and International Economic Law (Routledge 2015).

36 Blake (n 8) 11.

37 Ibid., 29.

38 Ibid., 42-3.

39 World Heritage Committee, The Yamato Declaration on Integrated Approaches for Safeguarding Tangible and Intangible Heritage, adopted during the Seventh Extraordinary Session of the World Heritage Committee, Doc.WHC-04/7 EXT. COM/INF.9, of 25 November 2004, paras 13 and 15. 
not only about relations among the different domains of heritage and legal mechanisms, but also the different purposes of ICH safeguarding. After all, while all UNESCO treaties are read under the UNESCO Constitution and its core objectives, the same cannot be said about instruments enacted under other organizational umbrellas. And, as discussed in the introduction, regional organizations tend to emphasize the shared features of their region, instead of universal aspirations. One such organization is the Council of Europe under which the Faro Convention has been created.

\section{THE FARO CONVENTION: INTANGIBLE HERITAGE DEFINED BY ITS VALUE TO SOCIETY}

From the outset, it is important to bear in mind that the Council of Europe and the European Union are two distinct regional organizations. This chapter focuses on the contribution of the former which materialized as the Faro Convention. ${ }^{40}$

There are several instruments within the Council of Europe dealing with heritage protection, but these instruments more often than not deal with specific forms of tangible heritage, such as architectural heritage, ${ }^{41}$ archaeological heritage, ${ }^{42}$ or landscapes. ${ }^{43}$ While it has been argued that several of these instruments offer sometimes contradictory approaches in distinguishing between local and international interests (among other conceptual issues), ${ }^{44}$ the fact is that these instruments have successfully proliferated and created a reliable net of standard-setting instruments.

40 This is not to suggest that the European Union has not engaged with regulating intangible cultural heritage, but that the study of their contribution on this point falls outside the purview of this chapter. For more on the EU regulation of intangible cultural heritage see: Lucas Lixinski, 'The Future of the EU Cultural Policy in the Protection of Intangible Cultural Heritage' (2009) 1 The Prague Yearbook of Comparative Law 119.

${ }_{41}$ Council of Europe, Convention for the Protection of the Architectural Heritage of Europe. Granada, 3 October 1985. ETS no 121. Entry into force: 1 December 1987.

42 Council of Europe, European Convention on the Protection of the Archaeological Heritage (Revised). Valetta, 16 January 1992. ETS no 143. Entry into force: 25 May 1995.

43 Council of Europe, European Landscape Convention. Florence, 20 October 2000. ETS no 176. Entry into force: 1 March 2004.

44 For an analysis of these issues, see Claude Karnoouh, 'Europe: Common Heritage and Differences' in Council of Europe (ed), Forward Planning: The Function of Cultural Heritage in a Changing Europe (Council of Europe, 2000). 
The Framework Convention on the Value of Cultural Heritage for Society (Faro, 2005), ${ }^{45}$ on the other hand, deals with heritage in a more abstract manner. It is the most important instrument for the purposes of intangible heritage protection in the Council of Europe system, because it addresses heritage in abstract terms, in line with the idea of intangibility. Its purpose is to create a 'European ideal' of social organization; instead of preserving difference, heritage is here used to create commonality. ${ }^{46}$ The contribution of heritage to society is seen in terms of its development for economic purposes, on the one hand, while at the same time advancing common European identity.

The Faro Convention is the least ratified of all Council of Europe treaties on cultural heritage, ${ }^{47}$ in stark contrast with the ICHC, which is one of the most widely ratified UNESCO treaties (in spite of also being the most recent one, like the Faro Convention in Europe). One of the reasons for reluctance to ratify the Faro Convention may precisely be its progressive take on cultural heritage and its safeguarding.

The Faro Convention was designed after a series of consultations were held with the aim of creating a new instrument, either a protocol to existing Council of Europe Conventions or a totally new treaty that could convey the latest understandings of cultural heritage, particularly its intangible aspects. ${ }^{48}$ It is innovative in speaking openly of a right to cultural heritage. This right, in the Convention, is an inherent part of the right to participate in cultural life, as protected by the Universal Declaration of Human Rights. ${ }^{49}$ Heritage is referred to as deriving directly from identity, and all references to heritage or culture as 'concrete

45 Council of Europe, Framework Convention on the Value of Cultural Heritage for Society (Faro Convention), Signed in Faro on 27 October 2005. ETS no 199. Entry into force: 1 June 2011.

46 Council of Europe, Presentation to the Framework Convention.

47 While the Faro Convention has been ratified by 17 States, the Valetta Convention has been ratified by 46 States, and the Granada Convention by 42 States (all at the time of writing). The only Council of Europe heritage treaty that has received less ratifications is the Council of Europe Convention on Offences relating to Cultural Property, CETS No.221, which was only approved in May 2017.

48 Council of Europe, Explanatory Report to the Council of Europe Framework Convention on the Value of Cultural Heritage to Society CETS 199 (Council of Europe Explanatory Report) (Council of Europe, 2005) <https://rm.coe.int/16800d3814> accessed 10 October 2017.

49 The relevant provisions are the following: 'Article 1 - Aims of the Convention. The Parties to this Convention agree to: a. recognise that rights relating to cultural heritage are inherent in the right to participate in cultural life, as defined in the Universal Declaration of Human Rights; [. . .]' and Article 4: 
entities' is avoided, thus also avoiding the commodification of heritage. ${ }^{50}$ This is not, however, an enforceable right, because of the very nature of a framework convention (in that it does not create self-executing norms, and therefore enforceable rights), and also because of an explicit provision announcing that the Convention does not create subjective rights of any sort. ${ }^{51}$ The 'right to heritage', therefore, is only declaratory in the Convention. ${ }^{52}$

Cultural heritage is defined as 'a group of resources inherited from the past which people identify, independently of ownership, as a reflection and expression of their constantly evolving values, beliefs, knowledge and traditions. It includes all aspects of the environment resulting from the interaction between people and places through time'. ${ }^{53}$ This definition highlights several issues relating to intangible heritage, particularly the idea of 'constantly evolving values', which indicates a living culture.

Much like the ICHC, this definition seems to impose a threshold requirement precluding the possibility of contemporary $\mathrm{ICH}$, when it speaks of the need for heritage to be 'inherited from the past', however defined (the drafting history is unclear on this matter). That said, its focus

Rights and responsibilities relating to cultural heritage. The Parties recognise that:

a. everyone, alone or collectively, has the right to benefit from the cultural heritage and to contribute towards its enrichment;

b. everyone, alone or collectively, has the responsibility to respect the cultural heritage of others as much as their own heritage, and consequently the common heritage of Europe;

c. exercise of the right to cultural heritage may be subject only to those restrictions which are necessary in a democratic society for the protection of the public interest and the rights and freedoms of others.

Please note that the right to heritage as protected in the Convention is a relative right, which can be limited subject to a proportionality analysis, like the rights to cultural identity and minority protection, as developed by adjudicatory bodies.

50 Council of Europe Explanatory Report (n 48).

51 The relevant provision is the following: 'Article 6-Effects of the Convention. No provision of this Convention shall be interpreted so as to: a. limit or undermine the human rights and fundamental freedoms which may be safeguarded by international instruments, in particular, the Universal Declaration of Human Rights and the Convention for the Protection of Human Rights and Fundamental Freedoms; b. affect more favourable provisions concerning cultural heritage and environment contained in other national or international legal instruments; c. create enforceable rights' (emphasis added).

52 This view is reinforced by the Explanatory Report to the Convention, see Council of Europe Explanatory Report (n 48).

53 Faro Convention, Article 2.a. 
on constantly evolving values and traditions is, much like in the ICHC, an important opening to keep heritage practices updated. Importantly, heritage in the Faro Convention is defined relationally, in accordance to the way society attributes value to it. While the same notion is present in the text of the ICHC, the implementation of the ICHC fails to live to that expectation because of its reliance on expert rule, or the prerogative of experts to determine what heritage is worth safeguarding, and what heritage does not merit international protection - a problem shared by all UNESCO treaties, to a certain extent. ${ }^{54}$ In contrast, the Faro Convention has been praised in the literature for its ability to create a heritage community separate from experts. ${ }^{55}$ In fact, the Faro Convention defines heritage community in the same article that defines cultural heritage, as 'people who value specific aspects of cultural heritage which they wish, within the framework of public action, to sustain and transmit to future generations'..$^{56}$

The Convention also defines the 'common heritage of Europe', as 'all forms of cultural heritage in Europe which together constitute a shared source of remembrance, understanding, identity, cohesion and creativity', and 'the ideals, principles and values, derived from the experience gained through progress and past conflicts, which foster the development of a peaceful and stable society, founded on respect for human rights, democracy and the rule of law', ${ }^{57}$ The first part of this double definition is cultural heritage explicitly, whereas the second part refers to the original understanding of 'common European heritage' of the founding of the Council of Europe. The idea of common European heritage in this Convention comes without the political charge originally associated with it, but still falls short of being merged into the idea of cultural heritage. Rather, there is a distinction there between the cultural heritage of Europe, on the one hand, and the shared intellectual heritage, which looks at the ideal of how a society should operate. ${ }^{58}$ These two elements are seen as being mutually-supportive, and a unifying idea in the Convention, which

54 On this critique, see Lucas Lixinski, 'International Cultural Heritage Regimes, International Law and the Politics of Expertise' (2013) 20(4) International Journal of Cultural Property 407.

55 See for example, John Schofield (ed.), Who Needs Experts? CounterMapping Cultural Heritage (Ashgate 2014). This volume is almost exclusively dedicated to the Faro Convention's disruption of the canon of expertise in cultural heritage.

56 Faro Convention, Art. 2.b.

57 Ibid., Art. 3.

58 Council of Europe Explanatory Report (n 48). 
refers back to the Declaration on Intercultural Dialogue and Conflict Prevention (the Opatija Declaration). ${ }^{59}$

This focus on values, rather than the constitutive elements of heritage, can also be seen as a further step towards avoiding the commodification of heritage, and it evidences a difference in approach from that of the 2003 UNESCO Convention. Another difference is that heritage is not protected in the Faro Convention as a goal in itself, but rather as also being instrumental in contributing to the lives of people and communities in Europe. ${ }^{60}$

The Faro Convention also addresses concerns associated with the economic dimensions of cultural heritage, a relationship that is otherwise underappreciated in international heritage instruments. Cultural heritage is seen as a factor in sustainable economic development, and economic policies must take into account cultural heritage and its integrity, which must not be compromised in what refers to its 'inherent values'. ${ }^{61}$ This latest provision recognizes that cultural heritage has a value that goes beyond its utility at a particular time and place, and must therefore be protected regardless of the purposes it serves, to respect the rights of communities and particularly future generations, which may find other purposes for heritage which can be lost if heritage is preserved only to the extent that it serves economic purposes. ${ }^{62}$

Finally, the Faro Convention imposes upon the parties the obligation to create a monitoring body through the Council of Europe, to oversee legislative practice and other policies regarding heritage. ${ }^{63}$ The Committee

59 Council of Europe, Summit on Heritage and Communication, Declaration of Opatija on Intercultural Dialogue and Conflict Prevention, Adopted at the Regional Summit Forum on Communication of Heritage on 1 June 2006.

60 Council of Europe Explanatory Report (n 48).

${ }_{61}$ The relevant provision is the following:

Article 10 - Cultural heritage and economic activity. In order to make full use of the potential of the cultural heritage as a factor in sustainable economic development, the Parties undertake to: a. raise awareness and utilise the economic potential of the cultural heritage; $b$. take into account the specific character and interests of the cultural heritage when devising economic policies; and c. ensure that these policies respect the integrity of the cultural heritage without compromising its inherent values.

62 Council of Europe Explanatory Report (n 48).

63 The relevant provision is the following:

Article 15-Undertakings of the Parties. The Parties undertake to: a. develop, through the Council of Europe, a monitoring function covering legislations, policies and practices concerning cultural heritage, consistent with the principles established by this Convention; b. maintain, develop and 
of Ministers received the mandate to create this body or delegate authority to an existing one to oversee the application of the Convention. ${ }^{64}$ The Steering Committee for Cultural Heritage and Landscape is in charge of overseeing the implementation of the Faro Convention, but it seems its role is somewhat secondary, as there is a sense in which the authoritative interpretation and enforcement of heritage treaties is beyond the remit of the Council of Europe, and intentionally left to States Parties, better able to define culture and priorities in that realm. ${ }^{65}$

Much of the implementation action is targeted at creating an information system about national implementation of the instrument. Further action offers the means for effective protection of ICH through preventive safeguarding via educational programmes and awareness-raising. Importantly, a number of initiatives under the Faro Convention aim at subverting normal expectations about heritage protection. For one, any listing system under the Faro Convention focuses on listing best practices, rather than heritage itself. It also offers recognitions to communities, rather than their cultural manifestations, thus more firmly focusing on social context rather than cultural performances (an objective attempted by the ICHC, but somehow frustrated by the two main listing mechanisms). The Faro Convention implementation action goes as far as claiming that the

contribute data to a shared information system, accessible to the public, which facilitates assessment of how each Party fulfils its commitments under this Convention.

64 The relevant provision is the following:

Article 16-Monitoring mechanism.

a. The Committee of Ministers, pursuant to Article 17 of the Statute of the Council of Europe, shall nominate an appropriate committee or specify an existing committee to monitor the application of the Convention, which will be authorised to make rules for the conduct of its business;

b. The nominated committee shall:- establish rules of procedure as necessary; - manage the shared information system referred to in Article 15 , maintaining an overview of the means by which each commitment under this Convention is met; - at the request of one or more Parties, give an advisory opinion on any question relating to the interpretation of the convention, taking into consideration all Council of Europe legal instruments; - on the initiative of one or more Parties, undertake an evaluation of any aspect of their implementation of the Convention;--foster the trans-sectoral application of this Convention by collaborating with other committees and participating in other initiatives of the Council of Europe; - report to the Committee of Ministers on its activities. The committee may involve experts and observers in its work.

65 Sarah Wolferstan, 'Ethnography of a "Humble Expert": Experiencing Faro' in Schofield (n 55) 45. 
community themselves are the heritage. ${ }^{66}$ Key in this respect is the fact that the large majority of implementation actions currently overseen by the Council of Europe for the Faro Convention involve civic elements very centrally, unlike the ICHC mechanisms, that still rely primarily on States themselves.

The Faro Convention also takes a new approach when it comes to information-sharing with respect to best practices in heritage safeguarding: instead of reporting by States to the Council of Europe, communities within States Parties are invited to enter information in a shared database themselves, which should speed up the process of collecting data and compiling repertoires of best practices for the protection of heritage. This is a laudable development in two respects: first, it takes into account the developments of the information society; secondly, as stressed above, it makes communities themselves much more central to the safeguarding process. Hopefully, this will help the Convention achieve its aims and offer better integrated protection to heritage, in its tangible and intangible aspects.

In practice, thus, it seems that the Faro Convention is a treaty under Article 3 of the ICHC, that needs to be taken into account in considering its implementation. But the modes of action are very different, and there seems to be little to no overlap to worry about. The more fundamental tension is a theoretical one, in that the Faro Convention seems to achieve what the ICHC only promised, but has fallen somewhat short of: making communities a central part of heritage safeguarding practices, and privileging heritage for its role in society, rather than as an end in itself.

Seen as mutually reinforcing, taken together those treaties mean a true redefinition of heritage management paradigms. That said, they only apply to countries that have ratified both the ICHC and the Faro Convention. This means that they apply only in Europe, and to merely about one-third of European countries, at the time of writing.

In terms of what the Faro Convention, and its overlap with the ICHC, means for the politics of regionalism in international heritage law, one thing is clear: the Faro Convention has gone farther than the ICHC could, and that can only be explained in reference to a strong regional legal framework, and shared values when it comes to heritage management in Europe. That said, the Faro Convention's Article 3, in pushing for the primacy of shared European identity, also has distorting effects on what we consider

66 Council of Europe, 'Faro Initiatives' (Council of Europe Official website) $<$ http://www.coe.int/t/dg4/cultureheritage/heritage/Identities/initiatives_en.asp> accessed 10 October 2017. 
heritage worth pursuing, and what communities get to be recognized for their practices in heritage safeguarding (and consequently have their heritage recognized). In this way, the Faro Convention selects heritage in a very specific way, that can be seen to be at odds with the "representativeness" mandate of the ICHC. This type of selectivity is common when speaking of regional arrangements with respect to heritage, particularly $\mathrm{ICH}$, which is seen as more volatile and closer to political identity. ${ }^{67}$ But taken together the two effectively complement each other, and providing a stronger framework for safeguarding ICH. That said, neither seems particularly apt at welcoming contemporary forms of ICH into their fold, because of the intergenerationality thresholds present in the definition of heritage each treaty provides.

\section{CONCLUDING REMARKS: INTANGIBLE CULTURAL HERITAGE AND CONTEMPORARY CULTURE IN THE LAW}

In terms of definition, cultural heritage has a complicated relationship with the present, seen as it is fixated in the past. But the turn towards safeguarding and social processes, attempted first by the ICHC and perhaps best executed by the Faro Convention, is promising, in that it privileges interactions with culture over the culture itself. In doing so, communities come front and centre, and socio-cultural processes become the heritage (or even communities themselves). That is a welcome step, but taken in the broader context of international heritage law, there is too much of a pull to focus on the past coming from heritage law and management practice. So, instead of seeking an entry into these systems through the definitions, the best that can possibly be hoped for is to rely on their embracing of safeguarding practices as a means to bring the contemporary into the fold of ICH, even if only indirectly. To have a safeguarding practice recognized and listed does not seem to require the same threshold of cross-generation use; to the contrary, a safeguarding practice is meant to be contemporary, even if it can rely on elements from the past.

The survey of these two treaties above also showcases tensions between universal and regional approaches to heritage protection, and it reminds us that the situation in Europe is very different from the one in the Americas, for instance, or in Africa or Asia. But the interpretation of the ICHC read

${ }^{67}$ For more on this point see, Lixinski Intangible Cultural Heritage in International Law (n 1) 102-103. 
34 Research handbook on contemporary intangible cultural heritage

in light of the Faro Convention can lead to better safeguarding practices that, if added to the proper ICHC inventory, can have an impact across the world. In this way, regionalism has a 'trickle up, and then back down elsewhere' effect. But one must remain alert to the selectivity of regional heritage law, and what it means for the representativeness of ICH worldwide, of which contemporary culture hopes to one day become a part. 